\title{
As condicionantes nos licenciamentos ambientais para a fase de operação de rodovias: um estudo de caso no Estado do Rio Grande do Sul, Brasil
}

\section{Dênis Silvano Domingues ${ }^{1}$, Marilia Teresinha Hartmann', Cristhian Magnus de Marco $^{2}$ e Paulo Afonso Hartmann 3}

\author{
${ }^{1}$ Universidade Federal da Fronteira Sul . Programa de Pós -Graduação em Ciência e \\ Tecnologia Ambiental. Campus Erechim. Rodovia ERS-135, 200. Erechim-RS, Brasil \\ (CEP 99700-970). \\ ${ }^{2}$ Universidade do Oeste de Santa Catarina. Programa de Pós-Graduação em Direito. \\ Campus Joaçaba. Rua Getúlio Vargas, 2.125. Flor da Serra. Joaçaba-SC, Brasil \\ (CEP 89600-000) \\ ${ }^{3}$ Universidade Federal da Fronteira Sul . Programa de Pós -Graduação em Ciência e \\ Tecnologia Ambiental. Campus Erechim. Rodovia ERS-135, 200. Erechim-RS, Brasil \\ (CEP 99700-970). E-mail: hartmann.paulo@gmail.com.
}

\begin{abstract}
Resumo. No Brasil, país com dimensões continentais, o transporte rodoviário é o principal modal utilizado, com 1,72 milhões $\mathrm{km}$ de rodovias pavimentadas e não pavimentadas. Estradas e rodovias são consideradas como vetores de desenvolvimento, porém também são fonte de distúrbio antrópico no meio ambiente, como fragmentação da paisagem e mortalidade de fauna, representando uma real ameaça para a conservação da vida silvestre. Mesmo rodovias implementadas com o prévio Estudo de Impacto Ambiental/Relatório de Impacto ao Meio Ambiente (EIA/RIMA) e possuidoras das respectivas licenças ambientais, podem carecer de estudos técnicos complementares e sequenciais que permitam o monitoramento contínuo da biodiversidade, mostrando-se insuficientes e ineficazes aos fins que se destinam. Neste sentido, a integração da infraestrutura existente e a previsão e mitigação de impactos dos novos empreendimentos se configura como um grande desafio socioambiental. Este estudo teve por objetivo identificar os critérios técnicos e jurídicos que nortearam as condicionantes ambientais e expressas nos licenciamentos das rodovias da região norte do Estado do Rio Grande do Sul, identificando eventuais carências ou inconsistências hábeis à efetividade na implantação e à redução dos impactos ambientais. Para tal foram avaliados os documentos referentes aos licenciamentos ambientais de três rodovias no Estado do Rio Grande do Sul, as condicionantes ambientais previstas, os regramentos técnicos norteadores, as ações realizadas para a regularização das rodovias, e os desdobramentos legais para sua aplicabilidade. 0 procedimento de licenciamento ambiental vigente para as rodovias analisadas
\end{abstract}

Recebido

$14 / 09 / 2021$

Aceito

$24 / 11 / 2021$

Disponível on line $24 / 11 / 2021$

Publicado

$31 / 12 / 2021$

Acesso aberto

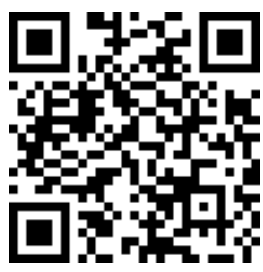

0000-0002-7290-6384

Dênis Silvano

Domingues

ISSN 2359-1412/RBGAS-2021-0117/2021/8/20/8/1381

Rev. Bras. Gest. Amb. Sustent.

http://revista.ecogestaobrasil.net 
sinaliza com decisões conflitantes que inviabilizam os fins desejados e necessitam de aprimoramentos para uma maior proteção ambiental. A efetiva participação das partes envolvidas no processo técnico de licenciamento ambiental de rodovias contribui positivamente para a celeridade processual e evita judicialização. A clareza nos regramentos a serem cumpridos, tanto pelo licenciador como pelo licenciado, além de ser mais benéfica a ambos, contempla a segurança jurídica e salvaguarda a transparência nos procedimentos fiscalizatórios e renovadores dos licenciamentos.

Palavras-chave: Legislação ambiental; Impacto ambiental; Medidas mitigadoras; Fauna.

Abstract. The environmental licensing requirements for the operation of highways: A case study in the State of Rio Grande Sul, Brazil. In Brazil, a country with continental dimensions, road transport is the main modal used with 1.72 million $\mathrm{km}$ of paved and unpaved roads. Highways are considered as vectors of development and represent a source of anthropic disturbance to the environment, such as fragmentation of the landscape and high mortality of fauna, representing a real threat to the conservation of wildlife. Even highways implemented with the previous environmental impact studies and with the respective environmental licenses, may lack complementary and sequential technical studies that allow the continuous monitoring of biodiversity, showing to be insufficient and ineffective for their intended purposes. The integration of the existing infrastructure and the forecasting and mitigation of the impacts of new projects is a major challenge. This study aimed to identify the technical and legal criteria that guided the environmental conditions and expressed in the licenses of the highways of the northern region of State of Rio Grande do Sul, identifying any deficiencies or inconsistencies that are effective in the implementation and reduction of environmental impacts. We analyzed the documents referring to the environmental license of three highways in the north of State of Rio Grande Sul, the environmental conditions envisaged, the guiding technical rules; the actions taken to regularize the highways, and the legal ramifications for its applicability. The current environmental licensing procedure for highways signals conflicting decisions that make the desired ends unfeasible and need improvements for greater environmental protection. The effective participation of all stakeholders involved in the environmental licensing promote a faster process and avoid judicialization. Clarity in the rules is positive to environmental licensing because provides legal certainty and safeguards transparency in the inspection procedures and licensing renewals.

Keywords: Environmental legislation; Environmental impact; Mitigation measures; Fauna.
D) $0000-0002-2473-1276$

Marilia Teresinha

Hartmann

D) $0000-0003-4528-6690$

Cristhian Magnus de

Marco

(C) 0000-0003-1417-0409

Paulo Afonso

Hartmann 


\section{Introdução}

As rodovias são empreendimentos essenciais à vida humana, posto que facilitam o deslocamento de pessoas e produtos, gerando assim desenvolvimento social e econômico para regiões (Bager et al., 2016). Agregam também fortalecimento ao desenvolvimento humano, uma vez que auxiliam no acesso a saúde, a educação, a empregos e facilita a ocupação da terra por pessoas (Perz et al., 2008). No Brasil, a partir de 1920, ampliam-se os financiamentos para a abertura de estradas, iniciando o chamado modelo 'rodoviarista'. 0 Brasil possui mais de $8.500 .000 \mathrm{~km}^{2}$, território que apresenta uma grande diversidade de paisagens e biomas. Em um país de dimensões continentais, o transporte rodoviário é o principal modal utilizado (Bager et al., 2016).

Segundo dados da Confederação Nacional do Transporte (CNT), o Brasil possui 1,72 milhões km de rodovias pavimentadas e não pavimentadas. Desse total, $93 \%$ são de rodovias estaduais, transitórias, estaduais e municipais e 7\% são de estradas federais. As estradas não pavimentadas são a maioria (87,6\%), contra apenas $12,4 \%$ de rodovias pavimentadas (CNT, 2020).

A escolha pelo transporte rodoviário trouxe incrustado diversas consequências ambientais. Rodovias são consideradas como vetores de desenvolvimento para as sociedades humanas, entretanto, ao mesmo tempo representam uma fonte de distúrbio antrópico para o meio ambiente (Forman e Alexander, 1998). As rodovias estão entre as alterações ambientais que causaram impactos mais extensos em paisagens naturais no século XX (Bergallo e Vera y Conde, 2001). Nas estradas ocorrem problemas ambientais relacionados a fragmentação da paisagem e atropelamentos da fauna, com consequente alta mortalidade de animais silvestres (Bager et al., 2007; Bager e Rosa, 2011). Os efeitos ecológicos não se restringem à estrada, mas estendem-se pela paisagem no entorno, gerando impactos físicos, como erosão e alteração da hidrologia local; químicos, como dispersão de poluentes; e biológicos, como destruição de ambientes naturais, efeito de barreira subdividindo populações e atropelamentos (Forman e Alexander, 1998).

As rodovias representam uma real ameaça para a conservação da vida selvagem globalmente (Trombulak e Frissell, 2000; Jaeger et al., 2005; Hartmann et al., 2011). As estradas podem causar alterações no comportamento animal, modificando os padrões de movimentação; fragmentação do habitat e isolamento populacional; degradação da qualidade da água; perda de indivíduos na construção das rodovias; mortalidade por colisão com veículos, introdução de espécies exóticas e disseminação de doenças (Coffin, 2007; Hartmann et al., 2011; Santana, 2012).

O sistema rodoviário oportuniza todo um contingente de benefícios para a sociedade, entretanto, a não observância efetiva de mecanismos legais vigentes potencializam os impactos ambientais, provocando alterações reversíveis e irreversíveis nos meios bióticos, físico, químico e antrópico da região onde inserido (Silva, 2017). A conservação da biodiversidade é um dos maiores desafios da humanidade devido ao elevado nível de perturbação antrópica nos ecossistemas (Metzger et al., 2009; Almeida et al., 2016).

No Brasil, o licenciamento ambiental de atividades e obras utilizadoras de recursos naturais ou potencialmente poluidoras teve início em meados da década de 1980 (Câmara, 2013). Até então, a malha rodoviária brasileira não teve considerada em sua implantação a perspectiva ecológica e de avaliação de seus impactos, resultando na geração de impactos que poderiam ter sido evitados (Lauxen, 2012). A construção de novas rodovias ou a ampliação da capacidade daquelas existentes está sujeita ao licenciamento ambiental (Brasil, 1997), processo no qual devem ser identificados seus impactos, avaliada sua viabilidade e prevê medidas preventivas, mitigadoras e compensatórias. 
A integração da infraestrutura existente e a previsão e mitigação de impactos dos novos empreendimentos se configura como o grande desafio de pesquisadores, planejadores e gestores da área ambiental (Ahern et al., 2009). Considerando a crescente, urgente e emergente relevância da temática ambiental, tem-se buscado sanar esses impactos ou mitigá-los, promovendo uma interação entre transportes, poderes públicos, desenvolvimento, qualidade de vida e meio ambiente.

Neste cenário, as rodovias implantadas apresentam problemáticas socioambientais, posto que suas execuções não se mostram eficazes para a conservação da fauna e redução dos impactos ao meio ambiente. Rodovias implementadas com o prévio EIA/RIMA (Estudo de Impacto Ambiental/Relatório de Impacto ao Meio Ambiente), estudo eminentemente técnico multidisciplinar (Brasil, 1986), e possuidoras das respectivas licenças ambientais, podem carecer de estudos técnicos complementares e sequenciais que permitam o monitoramento contínuo da biodiversidade, mostrando-se insuficientes e ineficazes aos fins que se destinam. Tendo em vista estas limitações, o objetivo do estudo foi analisar os critérios técnicos e jurídicos que nortearam os expedientes administrativos de licenciamento de rodovias no Estado do Rio Grande do Sul, apurando se os mesmos são suficientes para a redução dos impactos ambientais e a minimização da mortandade da fauna decorrentes da operação das rodovias, identificando eventuais carências e inconsistências no processo de licenciamento, com abordagem acerca dos principais desafios a serem superados.

\section{Métodos}

\section{Área de estudo e rodovias selecionadas}

Foi adotado como parâmetro amostral a fonte de dados os expedientes administrativos de três rodovias da região norte do Estado do Rio Grande do Sul, denominada Alto Uruguai, mais precisamente, a ERS-135, trecho Erechim ao entroncamento da BR-285, a ERS-420, trecho Aratiba à Volta do Uvá, e a ERS-480, trecho Barão de Cotegipe à Ponte Preta. As rodovias selecionadas atendem aos critérios pré-definidos: rodovias pavimentadas, de pista simples, e inseridas na mesma macrorregião, no caso, a região norte do Estado do Rio Grande do Sul, denominada Alto Uruguai.

\section{Região do Alto Uruguai}

A região norte do Estado do Rio Grande do Sul foi marcada historicamente pelo desmatamento intenso e consequente fragmentação ambiental (Martinazzo, 2011). Sua rede viária perpassa relevos planos e ondulados, rios, fragmentos florestais e áreas protegidas. O Alto Uruguai Gaúcho é uma denominação de uso frequente atribuída a um espaço cuja identidade advém de um conceito de Geomorfologia Fluvial ao se referir ao curso superior de um rio - Rio Uruguai (Piran, 2015). A vegetação local apresenta características de dois tipos de formações florestais, a Floresta Ombrófila Mista e a Floresta Estacional Decidual, com vegetação composta por uma diversidade de espécies distribuídas ao longo dos remanescentes em terrenos ondulados e vales bem marcados ao longo dos rios principais e seus afluentes (Rio Grande do Sul, 2010). A região integra parte da área da Reserva da Biosfera da Mata Atlântica e inclui, dentro de seus limites, unidades de conservação, áreas indígenas, sítios arqueológicos e comunidades quilombolas.

\section{Rodovias analisadas}

ERS-135. A rodovia ERS-135 liga os Municípios de Passo Fundo e Jacutinga, e, ao longo de sua extensão, cruza Coxilha, Sertão, Getúlio Vargas e Erechim. Possui o total de 79,89 km de extensão e é considerada longitudinal pela direção e sentido que percorre (EGR, 2021). Teve como trecho amostral o segmento compreendido 
de Erechim ao entroncamento da BR 285. A Empresa Gaúcha de Rodovias (EGR) administra 78,330 km da rodovia, de Passo Fundo à Erechim, assim como o pedágio comunitário situado em Coxilha. Os acessos aos Municípios Lindeiros foram concebidos com as obras e serviços realizados com a arrecadação da praça (EGR, 2021).

ERS-420. A rodovia ERS-420, classificada como rodovia de ligação, teve como trecho amostral estudado o segmento compreendido de Aratiba à Volta do Uvá. 0 trecho amostral da ERS 420 teve como empreendedor o Município de Aratiba, licenciado junto à Fundação Estadual de Proteção Ambiental Henrique Luiz Roessler (FEPAM) a promover a instalação relativa à pavimentação asfáltica de $18,00 \mathrm{~km}$.

ERS-480. A rodovia ERS-480, classificada como rodovia de ligação, teve como trecho amostral estudado o segmento compreendido de Barão de Cotegipe à Ponte Preta. O trecho amostral da rodovia ERS-480, teve como empreendedor o Departamento Autônomo de Estradas de Rodagem (DAER), licenciado junto à FEPAM com $13,29 \mathrm{~km}$.

\section{Análise documental}

Para as três rodovias estaduais selecionadas foram avaliadas as documentações referentes aos procedimentos administrativos acerca dos licenciamentos ambientais, suas respectivas condicionantes, os regramentos técnicos norteadores, as ações realizadas para as regularizações e os desdobramentos legais para sua aplicabilidade, com considerações de seus reais efeitos, identificando eventuais inconsistências hábeis na sua operacionalidade

Para a análise dos dados coletados foram analisadas as condicionantes ambientais, considerando: os estudos prévios realizados; a metodologia utilizada para estimativa de impactos; bases científicas adotadas; e, medidas mitigadoras propostas. Também foi analisado o resultado almejado com o produto encontrado, identificando possíveis inconsistências para a redução dos impactos sobre a fauna para a operação das rodovias.

Neste contexto, os dados coletados foram analisados e interpretados adotando como parâmetro a situação hipotética ilustrada, onde temos que um ato estatal que limita um direito fundamental somente faz-se necessário caso a realização do objetivo perseguido não possa ser promovido, com a mesma intensidade, por meio de outro que limite, em menor medida, o direito fundamental atingido.

\section{Resultados}

\section{ERS-135}

Expediente Administrativo de Licenciamento Ambiental no 10043-05.67/15-0

Através do Processo Administrativo no 10043-05.67/15-0, a EGR protocolou junto à Fundação Estadual de Proteção Ambiental Henrique Luiz Roessler (FEPAM), órgão licenciador estadual, em 14 de dezembro de 2015, documentação técnica hábil para a análise e emissão de Licença de Operação da ERS-135, do trecho Erechim ao entroncamento da BR-285.

Licença de Operação no 02269/2016-DL

Compulsando o expediente administrativo no 10043-05.67/15-0, extrai-se que a rodovia possuía LO (Licença de Operação) no 02269/2016-DL, a qual licenciou 78,33 km da Rodovia ERS-135, iniciando no Município de Passo Fundo e terminando no Município de Erechim, ambos no Rio Grande do Sul, sem a pretérita emissão de LP (licença prévia) e LI (licença de instalação). 
No campo 'II. Das Condições e Restrições' da Licença de Operação no 02269/2016DL, denota-se do item '1. Quanto ao Empreendimento', subitem '1.5', que: "1.5 - as informações, estudos e dados técnicos que embasaram o licenciamento ambiental do presente empreendimento são de responsabilidade de (o documento apresenta a nominada da equipe técnica do empreendedor responsável pela supervisão ambiental do empreendimento, com nome, formação, e anotação de responsabilidade técnica (ART) de cargo e função), e sob responsabilidade do empreendedor:".

Ainda, no item '4. Quanto às Medidas de Controle Ambiental', subitem '4.1', que: "4.1 - deverão ser adotadas medidas preventivas e mitigadoras: 4.1 .1 - para os locais/pontos objeto de estabilização geotécnica no segmento rodoviário e, caso necessário, fazer uso de manta/malha anti-erosiva ou estruturas de contenção de processos erosivos, com intuito de garantir a segurança de tráfego e ambiental; 4.1 .2 - para os locais/pontos identificados como ambientalmente sensíveis, como potenciais corredores ecológicos, APPs, remanescentes florestais, mananciais hídricos;".

Também, no item '5. Quanto à Supervisão Ambiental', subitem '5.1' e '5.2', que: “5.1 - deverá ser contínua e com o intuito de controlar e minimizar os impactos provenientes da operação da rodovia sobre os solos, os recursos hídricos e a biodiversidade existentes, bem como fazer cumprir os planos e programas ambientais e de emergência, além de respeitar as condições e restrições desta licença; 5.2 - deverá ser apresentado anualmente, a título de juntada ao respectivo processo administrativo, Relatório de Supervisão Ambiental, com a relação das providências tomadas em atendimento às condições e restrições desta Licença, juntamente com memorial descritivo e fotográfico, tudo devidamente acompanhado pelas ARTs inerentes, destacando: 5.2.1 - referente ao Programa de Proteção à Fauna, o Relatório de Supervisão Ambiental deverá dar atenção especial aos pontos-chave (segmentos) identificados como sendo de maior ocorrência de impactos sobre a fauna, relatando a adoção de medidas mitigadoras e de controle ambiental que visam a redução destes impactos".

No campo 'III. Documentos a apresentar para renovação desta Licença', tem-se: "9. Relatório de Situação Ambiental contendo: - plantas e imagens de satélites coloridas, representativas e voltadas às questões de impacto ambiental com localização espacial do empreendimento, demarcação do $\mathrm{km}$ inicial e $\mathrm{km}$ final do trecho rodoviário, seções-tipo (somente algumas transversais), identificando as principais obras-de-arte, demarcação dos segmentos pavimentados e demais dados na legenda (apresentar o projeto geométrico somente em DVD); - memorial descritivo e ilustrado das obras-de-arte especiais existentes; memorial descritivo e ilustrado das nascentes e transposições de cursos d'água localizados na área de influência direta da rodovia, junto com as respectivas áreas de preservação permanente (APP); 10. Programa de Supervisão Ambiental voltado à operação da rodovia contemplando as ações contínuas de Proteção das Nascentes e Mananciais; Sinalização Ambiental e de Segurança; Preservação e Controle de Processos Erosivos; Proteção à Fauna e Remanescentes Florestais Nativos; Monitoramento e Controle do Atropelamento da Fauna; Intervenção em Vegetação e Transplante Florestal; Gerenciamento de Áreas de Preservação Permanente; Recomposição da Mata Nativa e Reposição Florestal Obrigatória; Gerenciamento de Riscos Ambientais; Comunicação Social e Educação Ambiental; Medidas Preventivas, Mitigadoras e Compensatórias; dentre outras que forem julgadas necessárias; deverá conter o cronograma executivo e Anotação de Responsabilidade Técnica (ART) dos profissionais responsáveis pelos estudos e pelos estudos e pelo monitoramento contínuo". Esta licença ambiental fora emitida em 02 de maio de 2016, com validade para as condicionantes explicitadas até 02 de maio de 2020.

Expediente administrativo de licenciamento ambiental № 50057-05.67/17-5

Através do Processo Administrativo no 50057-05.67/17-5, a EGR protocolou, tempestivamente, junto à FEPAM, em 09 de janeiro de 2017, documentação técnica hábil para a análise e renovação da Licença de Operação com abrangência de um dos núcleos 
rodoviários da EGR, dentre o segmento da ERS-135, do trecho Erechim ao entroncamento da BR 285.

Licença de Operação no 03690/2019

A Licença Ambiental (LO no 2269/2016-DL) foi revogada pela LO no 03690/2019, esta, com abrangência de um dos núcleos rodoviários da EGR. Conforme denota-se da Licença Ambiental supra (LO no 03690/2019), o licenciamento abrangeu a totalidade do Núcleo Rodoviário 02, este cobrindo uma extensão em 314,34 km, compreendendo a ERS129, a ERS-130, a ERS-135 e a RSC-287.

Além do trecho da ERS-135 (Passo Fundo - Erechim), abarcou também três outros segmentos de pavimentação, quais sejam a RSC-287 (Tabaí - Paraíso do Sul), com extensão de 148,65 km, ERS-129 (Encantado - Guaporé), com extensão de 59,28 km, e ERS-130 (Lajeado - Encantado), com extensão de 28,08 km.

Para o licenciamento dos 314,34 km, na LO no 03690/2019, do campo 'II. Condições e Restrições' extrai-se do item '3. Quanto à Preservação e Conservação Ambiental', subitem '3.1', que: "3.1 - áreas ambientalmente sensíveis, tais como locais de mananciais hídricos e áreas protegidas, deverão ter seus trechos sinalizados".

No item '6. Quanto à Flora', traz que: "6.1 - deverão ser preservados, em qualquer situação, os exemplares das espécies vegetais protegidas ocorrentes na gleba, conforme Lei Estadual 9519/92, Decreto Estadual no 52.109/2014 e Lista da Flora Ameaçada conforme Portaria MMA no 443/2014".

Ainda, no item '7. Quanto à Fauna', subitem '7.1', que: "7.1 - deve ser efetuado o monitoramento da fauna conforme estabelecido na Diretriz Técnica no 06/2018-FEPAM;". Também, no item '8. Quanto às Medidas de Controle Ambiental', subitem '8.1', que: "8.1 deverão ser adotadas medidas preventivas e mitigadoras para locais/pontos que são objeto de instabilidade geotécnica, devendo ser implantadas estruturas de contenção de processos erosivos, com intuito de garantir a segurança de tráfego e ambiental;".

No item '9. Quanto à Supervisão Ambiental', tem-se nos seus subitens: "9.1 - $a$ Supervisão Ambiental que deverá zelar pelo cumprimento do estabelecido nesta licença, assim como implementar os planos ambientais propostos relativos à operação e manutenção do empreendimento supracitado; 9.2 - deverá ser contínua e com o intuito de controlar e minimizar os impactos provenientes da operação do empreendimento sobre os recursos naturais, físicos e biológicos, primando pela busca de alternativas para cessação ou minimização do impacto e correção de não conformidades, bem como fazer cumprir os planos e programas ambientais e de emergência, além de respeitar as condições e restrições desta licença; 9.3 - deverá ser apresentado anualmente, na primeira quinzena de janeiro, o Relatório de Supervisão Ambiental, com a relação das providências tomadas em atendimento às condições e restrição desta Licença, juntamente com memorial descritivo e fotográfico, tudo devidamente acompanhado pelas ARTs inerentes, destacando: 9.3.1 - com referência a Proteção à Fauna, o Relatório deverá dar atenção especial aos hotspots identificados no monitoramento da fauna, trazendo proposições de adoção de medidas mitigadoras e de controle ambiental que visam a redução destes impactos;". A licença ambiental para o Núcleo Rodoviário 02 fora emitida em 27 de maio de 2019, com validade para as condicionantes explicitadas até 30 de maio de 2022.

\section{ERS-420}

Expediente administrativo de licenciamento ambiental no 1837-05.67/17-2

O Processo Administrativo no 1837-05.67/17-2 licenciou junto à FEPAM, em 2017, a pavimentação asfáltica de $18,00 \mathrm{~km}$ da rodovia ERS-420, trecho compreendido entre Aratiba à Volta do Uvá, tendo como empreendedor o Município de Aratiba-RS.

Licença de instalação no 00393/2017 
O Procedimento Administrativo no 1837-05.67/17.2 gerou a Licença de Instalação no 00393/2017. 0 expediente administrativo da LI no 00393/2017, licenciou 18,00 km da Rodovia ERS-420.

Para o trecho rodoviário $\mathrm{km} 4+440$ ao $\mathrm{km} 21+620$ do campo 'II. Condições e Restrições' extrai-se do item '1. Quanto ao Empreendimento', subitens '1.1' e '1.2', que: "1.1 - esta Licença refere-se a obras de infraestrutura viária com atividade de pavimentação asfáltica de segmento específico da rodovia ERS-420, segmento com 17,18 quilometros de

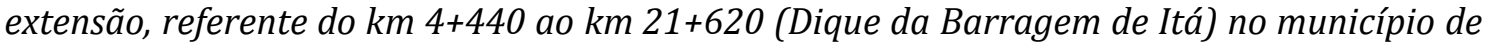
Aratiba - RS; 1.2 - esse empreendimento já foi objeto da LI no 37/97-DL e da LI no 555/2015$D L ; "$.

No item '3. Quanto à Fauna', subitens '3.1' e '3.2', que: "3.1 - é proibida a utilização, perseguição, destruição, caça ou apanha de animais silvestres, conforme legislação vigente; 3.2 - é proibida a intervenção em vegetação em áreas onde houver nidificação, devendo o empreendedor aguardar o término do período para proceder com corte e supressão;".

Também, no item '5. Quanto às Medidas de Controle Ambiental', no subitem '5.1', traz que: "5.1 - deverão ser adotadas medidas preventivas e mitigadoras: 5.1 .1 - para os locais/pontos objeto de estabilização geotécnica no segmento rodoviário e, caso necessário, fazer uso de manta/malha anti-erosiva ou estruturas de contenção de processos erosivos, com intuito de garantir a segurança de tráfego e ambiental; 5.1 .2 - para os locais/pontos identificados como ambientalmente sensíveis, como potenciais corredores ecológicos, APPS, remanescentes florestais, mananciais hídricos;".

Por fim, no item '6. Quanto à Supervisão Ambiental', subitens '6.1', '6.2' e '6.3', temse que: "6.1 - deverá ser contínua e com o intuito de controlar e minimizar os impactos provenientes da atividade proposta sobre os solos, os recursos hídricos e a biodiversidade existentes; monitorar as perturbações e possíveis desequilíbrios na fauna terrestre ocasionados pela implantação do empreendimento e nas intervenções emergenciais em vegetação nativa e em área de preservação permanente, cumprindo as condições e restrições desta licença; 6.2 - deverá ser apresentado Relatório de Supervisão Ambiental, com periodicidade ANUAL, referente ao acompanhamento contínuo das obras e do atendimento às condições e restrições desta licença, juntamente com memorial descritivo que relate sobre $o$ andamento das obras e relatório fotográfico, tudo devidamente acompanhado pelas ARTs dos responsáveis; 6.2.1 - deverá constar no Relatório Final de Supervisão Ambiental, declaração assinada pelo empreendedor informando sobre a conclusão das obras de implantação da rodovia, quanto ao cumprimento das condições e restrições da [Licença de Instalação ou Autorização], assim como a execução dos programas ambientais propostos $e$ as medidas mitigadoras/compensatórias definidas; 6.3 - a Equipe de Supervisão Ambiental e/ou a Equipe Técnica do Empreendedor deverão informar imediatamente à FEPAM, a ocorrência de qualquer situação verificada nas obras que esteja em desacordo com as restrições e condicionantes estabelecidas neste documento licenciatório".

No campo 'III. Documentos a apresentar para renovação da Licença de Instalação', dentre outros, a necessidade de apresentação nominada da equipe técnica do empreendedor responsável pela supervisão ambiental do empreendimento, com nome, formação, e-mail, telefones, e anotação de responsabilidade técnica (ART) de cargo e função, além de relatório de situação ambiental. A licença de instalação fora emitida em 21 de agosto de 2017, com validade para as condicionantes explicitadas até 23 de agosto de 2022.

\section{ERS-480}

Expediente administrativo de licenciamento ambiental no 7560-05.67/19-4

O Processo Administrativo no 7560-05.67/19.4 licenciou no ano de 2019, junto à FEPAM, o comprimento de 13,29 $\mathrm{km}$ da rodovia ERS-480, trecho compreendido entre 
Barão de Cotegipe à Ponte Preta, tendo como empreendedor o Departamento Autônomo de Estradas de Rodagem (DAER).

Licença de instalação no 00527/2019

O procedimento administrativo no 7560-05.67/19.4 gerou a Licença de Instalação no 00527/2019. O expediente administrativo supra (LI no 00527/2019), licenciou 13,29 km da Rodovia ERS-480.

Para o trecho rodoviário km $0+000$ (zona urbana, Barão de Cotegipe, RS) ao km $13+290$ (zona urbana, Ponte Preta, RS) do campo 'II. Condições e Restrições' extrai-se do item '2. Quanto à Preservação e Conservação Ambiental', subitens '2.1' e '2.2', que: "2.1 Ficam identificados aqui os seguintes ponto/locais ambientalmente sensíveis sendo locais identificados como potenciais corredores ecológicos, recantos de fauna, APP e conservação de remanescente florestal nativo: 2.1.1 - corredores ecológicos, recanto de fauna, APP $e$ conservação de remanescente florestal nativo, cita-se: corredor A (entre o $\mathrm{km} \mathrm{1+700} \mathrm{e} \mathrm{o} \mathrm{km}$ $2+700$ ), corredor $B$ (entre o $\mathrm{km} \mathrm{3+300} \mathrm{e} \mathrm{km} \mathrm{4+300),} \mathrm{corredor} \mathrm{C} \mathrm{(entre} \mathrm{o} \mathrm{km} 6+300$ e 6+700) e área no km 8+200, conforme apresentado no Processo administrativo no 6934-05.67/10-1; 2.2 - Deverá ser implantada sinalização ambiental em drenagens pluviais, áreas ambientalmente sensíveis, áreas susceptíveis à contaminação do solo, de áreas críticas para poluição ambiental, dos potenciais corredores ecológicos, dos recantos de fauna, dos recursos hídricos (APP), com destaque também à conservação de remanescente florestal nativo".

No item '5. Quanto à Fauna', subitens '5.1' e '5.2', que: “5.1 - Deve ser efetuado o monitoramento da fauna conforme estabelecido na Diretriz Técnica no 06/2018-FEPAM; 5.2 - O empreendedor deverá acompanhar os impactos decorrentes da implantação do empreendimento por meio de um programa de monitoramento da fauna; 5.2 .1 - 0 empreendedor deverá enviar relatório à FEPAM, juntamente com o Relatório de Supervisão Ambiental, contendo dados do monitoramento da fauna".

No campo 'III. Documentos a apresentar para renovação da Licença de Instalação', dentre outros, a necessidade de apresentação nominada da equipe técnica do empreendedor responsável pela supervisão ambiental do empreendimento, com nome, formação, e-mail, telefones, e anotação de responsabilidade técnica (ART) de cargo e função. A licença de instalação fora emitida em 26 de dezembro de 2019, com validade para as condicionantes explicitadas até 26 de dezembro de 2024.

A Tabela 1 apresenta a síntese das condicionantes previstas nas licenças de instalação e licença de operação das rodovias ERS-135, ERS-420 e ERS-480, no norte do Estado do Rio Grande do Sul.

\section{Instrução Normativa IBAMA no 13/2013}

Até a vigência da Diretriz Técnica FEPAM no 06/2018 (Rio Grande do Sul, 2018) as rodovias gaúchas eram licenciadas com observância ao teor da Instrução Normativa IBAMA no 13/2013 (Brasil, 2013).

A instrução normativa, dentre outros, estabeleceu os procedimentos para padronização metodológica dos planos de amostragem da fauna exigidos nos estudos ambientais necessários para o licenciamento ambiental de rodovias, com extensão para pós emissão da licença de instalação do respectivo empreendimento, ou seja, com continuidade de adoção após a emissão da licença de operação. Em complementação a Instrução Normativa IBAMA no 13/2013, a Diretriz Técnica FEPAM no 06/2018 trouxe novas condicionantes ambientais mais rigorosas e salutares para a minimização da mortandade da fauna em rodovias. 
Tabela 1. Síntese das Condicionantes previstas nas licenças de instalação e licença de operação das rodovias ERS-135, ERS-420 e ERS-480, no norte do Estado do Rio Grande do Sul. Sim = atende plenamente; Não = não atende; Parcial = presente na licença ambiental, mas não de forma plena.

\begin{tabular}{|l|c|c|c|}
\hline Licença ambiental (LI ou LO) & ERS-135 & ERS-420 & ERS-480 \\
\hline $\begin{array}{l}\text { Descrição da formação técnica dos } \\
\text { consultores / elaboradores }\end{array}$ & Sim & Não \\
\hline $\begin{array}{l}\text { Definição de métodos para estimativas de } \\
\text { impactos ambientais (gerais) }\end{array}$ & Sim & Não & Parcial \\
\hline $\begin{array}{l}\text { Definição de métodos para estimativas de } \\
\text { impactos dos atropelamentos de fauna }\end{array}$ & Sim* & Não & Parcial \\
\hline $\begin{array}{l}\text { Indicação dos grupos taxonômicos avaliados } \\
\text { / estudados }\end{array}$ & Sim* & Sim & Sim \\
\hline $\begin{array}{l}\text { Indicação de duração dos estudos e } \\
\text { periodicidade do monitoramento }\end{array}$ & Sim & Sim & Parcial \\
\hline Proposição de medidas mitigadoras & Sim & Não & Sim \\
\hline Proposição de medidas compensatórias das & Sim & Não & Parcial \\
\hline $\begin{array}{l}\text { Indicação de amparo técnico dam } \\
\text { condicionantes }\end{array}$ & Sim & Sim \\
\hline $\begin{array}{l}\text { Relação entre as condicionantes e os } \\
\text { impactos ambientais identificados na fase de } \\
\text { licenciamento }\end{array}$ & $\begin{array}{l}\text { Previsão de acompanhamento da execução } \\
\text { das condicionantes }\end{array}$ & Sim & Saron \\
\hline
\end{tabular}

* A partir da vigência da Diretriz Técnica FEPAM no 06/2018.

\section{Diretriz Técnica FEPAM no 06/2018}

A Diretriz Técnica FEPAM no 06/2018, referente ao termo de referência para o monitoramento de fauna em rodovias fundamenta-se nos ditames legais do Código Estadual do Meio Ambiente do Estado do Rio Grande do Sul.

Esta diretriz técnica traz em seu bojo, dentre outros, as definições de licença prévia (LP), licença prévia ambiental (LPA), licença prévia de instalação (LPI), licença prévia e de instalação para alteração (LPIA), licença prévia (LP) com EIA/RIMA, licença de instalação (LI), licença de instalação de ampliação (LIA), licença de operação (LO) e licença de operação (LO) de regularização, com diretrizes técnicas que atendem todas as tipologias possíveis de licenciamento de rodovias.

Para a solicitação de LP, LPA, LPIA, LP EIA/RIMA ou LIA, faz-se necessário o diagnóstico e um inventário de fauna, com metodologia, resultados, conclusões e recomendações para mitigar o impacto da via sobre a fauna. Para a solicitação de LPI ou LI, faz-se necessário o projeto de monitoramento para grupos individualizados com respostas e perguntas específicas sobre a mortandade.

Para a solicitação de LO, também a necessidade de projeto de monitoramento para grupos individualizados com respostas e perguntas específicas sobre a mortandade, sendo que, quando a LO for referente a núcleos rodoviários, o programa de monitoramento de fauna segue os mesmos critérios, mas com relatórios separados conforme cada rodovia específica do núcleo. Para a solicitação de LO de Regularização, o diagnóstico, o inventário de fauna, com metodologia, resultados, conclusões e recomendações para mitigar o impacto da via sobre a fauna, além de projeto de monitoramento para grupos individualizados com respostas e perguntas sobre a mortandade. 


\section{Discussão}

\section{Grande do Sul \\ As licenças para os empreendimentos rodoviários no norte do Estado do Rio}

Preliminarmente, insta destacar que a Diretriz Técnica FEPAM no 06/2018 (Rio Grande do Sul, 2018) não trouxe expressamente a revogação de nenhuma norma, o que significa dizer, crível a dedução de que o teor do termo de referência vigente, no modal proposto e nessa magnitude, era inexistente e não aplicado nos licenciamentos ambientais para as rodovias no Estado do Rio Grande do Sul. Por conseguinte, insta pontuar que a novel norma técnica não desobriga os licenciados no cumprimento das condicionantes expressas nas respectivas licenças ambientais. Os expedientes administrativos para os trechos amostrais e suas respectivas licenças ambientais indicam a existência de um conjunto de condicionantes expressas para minimizar os efeitos nocivos sobre a fauna.

Em análise individualizada para a ERS-135, denota-se da LO no 02269/2016-DL o trecho licenciado de 78,33 km, contendo expressamente, quanto ao empreendimento, referência a estudos e dados técnicos sob a responsabilidade de profissionais da biologia, geologia e engenharia, dentre outros. No tangente às medidas de controle e supervisão ambiental indica condicionantes preventivas e mitigadoras contínuas, com relatório anual, com identificação dos segmentos de maior ocorrência de impactos sofre a fauna e as medidas mitigadoras adotadas para redução destes impactos.

Para a renovação da LO no 02269/2016-DL, dentre outros documentos, o programa de supervisão ambiental contempla as ações contínuas de proteção, monitoramento e controle do atropelamento da fauna na operação da rodovia. Neste ponto, de suma importância destacar que inexistente a pretérita emissão da licença prévia e da licença de instalação, ou seja, não houve qualquer estudo técnico acerca da fauna preteritamente a implantação da rodovia, vez que os estudos técnicos existentes o foram para a licença de operação.

Por seu turno, quando da LO 03690/2019, o licenciamento ambiental abrangeu o Núcleo Rodoviário 2, totalizando 314,34 km, compreendendo a ERS-129, a ERS-130, a ERS-135 e a RSC-287, sendo que para os 78,33 km de extensão da ERS-135, trecho amostral de Passo Fundo - Erechim, contém expressamente as mesmas condicionantes para os demais trechos contidos no Núcleo Rodoviário 2 licenciado, o que não significa dizer que possuidores das mesmas características ambientais.

Para a totalidade em quilômetros do Núcleo Rodoviário 2, no que se refere à fauna, a licença ambiental traz expressamente o dever de monitoramento conforme estabelecido na Diretriz Técnica FEPAM no 06/2018, com medidas de controle e supervisão ambiental, preventivas e mitigadoras contínuas, com relatório anual, dentre a atenção especial aos hotspots (locais de concentração de atropelamentos) identificados no monitoramento e as medidas mitigadoras adotadas para redução destes impactos.

Em que pese a existência de um plano de mitigação dos impactos ambientais para a ERS-135, a falta de um melhor clareamento e detalhamento dos mecanismos a serem adotados para a sua efetiva aplicabilidade, colocam em dúvida sua eficácia. Aqui, oportuno referir que a Diretriz Técnica FEPAM no 06/2018 data de dezembro de 2018, ou seja, de momento posterior a emissão da Licença de Operação no 02269/2016-DL, esta em maio de 2016, o que nos permite questionar a efetividade das condicionantes pretéritas para os fins almejados, quais sejam, a minimização dos impactos ambientais e a redução na mortandade da fauna atropelada em rodovias.

Quando da análise do licenciamento ambiental para a ERS-420, temos que a LI no 00393/2017, licenciou a pavimentação asfáltica do trecho de $18,00 \mathrm{~km}$, contendo expressamente, quanto às medidas de controle e supervisão ambiental, condicionantes preventivas e mitigadoras contínuas, com relatório anual para o andamento das obras e observância às condições e restrições licenciadas. Considerando que o trecho amostral 
licenciado é para pavimentação asfáltica, inconteste que após a pavimentação do mesmo, o fluxo de veículos sobre a rodovia será mais intenso e veloz, o que certamente eleva o percentual de plausividade de aumento de atropelamento da fauna e, por conseguinte, acréscimo no numeral de mortalidade (Forman e Alexander, 1998; Van Der Ree et al., 2015).

As condicionantes previstas na Diretriz Técnica FEPAM no 06/2018 inexistiam quando da LI no 00393/2017, entretanto, igualmente resta inarredável a inexistência de condicionantes específicas na LI no 00393/2017, com o fim de minimizar os efeitos de atropelamento e mortandade da fauna após a conclusão das obras de pavimentação no trecho amostral da ERS-420.

Quando da análise do licenciamento ambiental para a ERS-480, denota-se que a LI no $00527 / 2019$, licenciou o trecho de $13,29 \mathrm{~km}$, contendo expressamente, quanto à preservação e conservação ambiental, identificação de pontos/locais ambientalmente sensíveis como potenciais corredores ecológicos e recantos de fauna. No referente à fauna, a licença ambiental estabelece o dever de monitoramento conforme estabelecido na Diretriz Técnica FEPAM no 06/2018, por meio de programa de monitoramento da fauna, emitindo relatório de supervisão ambiental contendo os dados monitorados da fauna.

Para o licenciamento ambiental do trecho amostral Barão de Cotegipe à Ponte Preta, considerando a vigência da Diretriz Técnica FEPAM no 06/2018, suas condicionantes restaram expressas seguindo o termo de referência para o monitoramento da fauna de conformidade com o que preceitua o Código Estadual do Meio Ambiente do Estado do Rio Grande do Sul.

Cediço que toda e qualquer intervenção antrópica no ambiente causa impactos de toda ordem no mesmo, sendo que quanto maior a obra de infraestrutura, maior serão os impactos gerados, o que se agrava, consideravelmente, tratando-se de rodovias quando inexistentes estudos técnicos que embasam as especificidades locais e carentes de mecanismos hábeis a minimização dos danos sobre a fauna (Karlson et al., 2014; Jaeger, 2015; Kindel et al., 2017).

Os procedimentos administrativos para os trechos amostrais que legitimaram a emissão dos respectivos licenciamentos possuem uma cadeia de etapas e ações que visam a instrumentalizar o processo de licenciamento, estando este em contínuo processo evolutivo, o que se permite extrair, de forma clara e cristalina, com a edição de Diretriz Técnica FEPAM no 06/2018, a qual traz em seu bojo diversas condicionantes até então inexistentes.

Em que pese a nova norma trazer em seu termo de referência inovações de louvor, o processo licitatório prescinde da inserção de todos os atores, direta e indiretamente envolvidos, participantes ativos do processo de 'negociação' de forma a instrumentalizar o procedimento de licenciamento, vez que transformar a 'diretriz técnica' e/ou outras normas em instrumento legal nos parece matéria simples, ao passo que a normativa técnica possui embasamento em publicações científicas.

A Diretriz Técnica FEPAM no 06/2018, atualmente vigente, no entanto se mostra de difícil aplicabilidade porque a modelagem adotada se mostra inviável por tratar-se de núcleos maiores, o que não impede que seja plausível para núcleos menores e com características ambientais muito próximas. Exemplificado, para trechos menores inexistiam instrumentos e mecanismos específicos para controle, monitoramento e minimização da mortandade da fauna em rodovias, fato comprovado pela edição da Diretriz Técnica FEPAM no 06/2018, somente que, a edição da norma técnica sem a instrumentalização institucional, por si só, não permite a fiscalização, o controle e o monitoramento da fauna vulnerável ao atropelamento em rodovias, o que se agrava, e muito, ao ampliar o segmento licenciado. 
Podemos considerar diversos fatores como entraves para uma aplicabilidade mais eficaz da Diretriz Técnica FEPAM no 06/2018, dentre a alta periodicidade de amostragens e um grau de detalhamento de informações de forma geral, ou seja, sem a observância das peculiaridades de cada trecho inserido dentro do núcleo maior. Ainda, a carência de regulamentação mínima acerca das 'perguntas' e 'respostas' específicas sobre a mortandade da fauna para o 'projeto de monitoramento'. Também, a ausência de ampliação da infraestrutura técnica administrativa hábil para a efetiva fiscalização do cumprimento das condicionantes previstas.

Os procedimentos administrativos de licenciamento que tratam da acurácia acerca da minimização da mortandade da fauna por atropelamentos em rodovias, em apertada síntese, pode ser dividida em dois momentos. 0 primeiro diz respeito à modelagem que licenciava trechos de rodovia individualmente e com condicionantes menos rigorosas. 0 segundo momento refere-se à edição da Diretriz Técnica FEPAM no 06/2018 que trouxe restrições e condicionantes específicas acerca do controle e monitoramento contínuo sobre os efeitos à fauna na operação de rodovias, entretanto, este mesmo modal, passou a licenciar núcleos rodoviários maiores e com características ambientais distintas, o que limita sua aplicabilidade e eficácia.

Exemplificando, da Licença Ambiental no 03690/2019, o qual prevê o monitoramento da fauna conforme estabelecido na Diretriz Técnica FEPAM no 06/2018, extrai-se que o licenciamento abrangeu a totalidade do Núcleo Rodoviário 02, com $314,34 \mathrm{~km}$, compreendendo a ERS-129 (Encantado à Guaporé com 59,28 km), a ERS-130 (Lajeado à Encantado com 28,08 km), a ERS-135 (Passo Fundo à Erechim com 78,33 km) e a RSC-287 (Tabaí à Paraíso do Sul com 48,65 km). Ao passo que trouxe mais condicionantes proativas para o monitoramento da fauna, ampliou a área licenciada com características ambientais distintas, ou seja, ao mesmo tempo, insere por um lado e retira por outro, instrumentos e mecanismos para o efetivo controle e monitoramento da mortandade da fauna atropelada em rodovias.

\section{ambientais \\ o processo de licenciamento de rodovias e a redução dos impactos \\ O Estado brasileiro há tempos fez a opção pelo modal rodoviário, o qual passa por} significativos processos evolutivos contínuos (Silva, 2019). Entretanto, os instrumentos e mecanismos de planejamento para a implantação de rodovias não seguem a mesma velocidade com que impactam os veículos que por elas trafegam. A carência de políticas públicas voltadas à proteção ambiental contribui para um cenário de descaso com o meio ambiente (Silva-Sánchez, 2000; Acselrad et al., 2004). Tudo no Brasil, na ótica ambiental, deveria funcionar nas perspectivas de sistema, mas alcançar esse olhar é um desafio gigantesco.

Inconteste que a tutela ambiental, dentre a salvaguarda da proteção da fauna nas rodovias, está sob a guarida do Estado, o qual possui o poder/dever de garantia dos direitos consagrados constitucionalmente (Mendes, 2004; Steinmetz, 2004; Garcia, 2007; Fensterseifer, 2008; Sarlet, 2010; Silva, 2013). Todas as normas infraconstitucionais que visam à proteção da fauna não podem fazer tabula rasa quando dos licenciamentos ambientais para a implantação e construção de rodovias, dentre a Lei no 6.938/1981 (Brasil, 1981), a Lei no 9.605/1998 (Brasil, 1998), a Lei no 9.985/2000 (Brasil, 2000) e a Lei no 12.651/2012 (Brasil, 2012).

Os licenciamentos ambientais para as fases de construção e operação das rodovias estão sob a tutela da análise técnica do órgão estadual licenciador ambiental, entretanto, a existência de significa parcela de rodovias carentes das LPs e LIs demonstram a fragilidade do próprio sistema (DNIT, 2015). Sem adentrar no mérito específico das causas que limitam o licenciamento ambiental para as rodovias, do quanto até aqui pesquisado, denota-se algumas razões que pesam para este cenário: a) a inexistência de Políticas 
Públicas efetivas voltadas a temática ambiental; b) a não valorização do material humano técnico disponível; c) o pouco uso da Academia como elemento técnico e científico apto na contribuição de proposições para novas amostragens, e; d) a carência da efetiva participação dos atores direta e indiretamente envolvidos.

Aqui é necessário pontuar que o engajamento participativo entre o licenciador (Estado) e os licenciados (empreendedores) tem o fito de busca conjunta de alternativas viáveis, salutares e exequíveis do processo como um todo, vez que a harmonia entre esses segmentos, elimina a judicialização de controvérsias, as quais são morosas e prejudiciais ao próprio sistema. Não se desconhece que a mudança na cultura daqueles interligados nos processos de construção e operação de rodovias, a saber: licenciador e licenciado, é tarefa árdua e que ainda necessita de longo caminho a ser trilhado. Somente que a edição da Diretriz Técnica FEPAM no 06/2018, a qual possuiu participação direta de responsável técnico Fundação Estadual de Proteção Ambiental Henrique Luiz Roessler (FEPAM), e significativa participação da equipe técnica acadêmica do Núcleo de Ecologia de Rodovias e Ferrovias (NERF), da Universidade Federal do Rio Grande do Sul (UFRGS), é prova inconteste da soma de esforços na mudança da perspectiva do gestor do próprio procedimento licenciatório, cujos frutos estão perceptíveis na própria Diretriz Técnica FEPAM no 06/2018 e em publicação científica (Kindel et al., 2017).

Todo e qualquer termo de referência que regula técnicas condicionantes licenciadas para as construções e operações de rodovias, precisam ser claras e objetivas quanto ao seu atendimento, como também possuir mecanismos que permitam sua viabilidade, tanto técnica como econômica, além da forma de controle e monitoramento do que pactuado entre as partes. Não se pode olvidar que o comprometimento da gestão ambiental do órgão oficial estadual licenciador, na contínua busca pelo aprimoramento dos mecanismos e instrumentos de controle da mortandade da fauna pela operação de rodovias, por si só, já gera resultados melhores e norteiam um ganho ambiental, vez que minimiza os danos ao macro ambiente.

Por outro viés, a 'inércia' do próprio Estado em não instrumentalizar tecnicamente o seu órgão licenciador, vai de encontro com todos os esforços daqueles servidores públicos técnicos efetivos, comprometidos com a salubridade ambiental. Esse louvável espírito ganha força com a 'parceria' das instituições acadêmicas, construindo embasamento científico hábil na formulação de normas técnicas/jurídicas legais no suporte aos gestores do instituto do licenciamento ambiental.

No atual cenário encontrado para o licenciamento das rodovias do Rio Grande do Sul, temos a Diretriz Técnica FEPAM no 06/2018 válida e em consonância com os anseios na minimização da mortandade da fauna. Entretanto, é de difícil aplicabilidade, pois foi idealizada para trechos menores, e o atual modal licencia um significativo número de rodovias e extensão em quilômetros, abrangendo 'núcleos' com características ambientais e especificidades próprias que tornam o próprio termo de referência incompatível e, por vezes, inócuo. No sentido de não agravamento ainda maior do ambiente e da perda da fauna por atropelamentos em rodovias, quanto mais clareza nos regramentos e maior a participação dos envolvidos, menores as possibilidades de judicialização, o que minimiza os prejuízos ambientais, sociais e econômicos, acrescendo de maior celeridade no processo como um todo.

Considerando a responsabilidade de 'todos' na busca pelo equilíbrio ecológico do meio ambiente, reconhecido como direito fundamental, conforme preceituado no caput do artigo 225, da Constituição Federal de 1988 (Brasil, 1988), a minimização da mortandade da fauna por atropelamentos em rodovias é matéria que persiste e deve ser continuamente perseguida por todos aqueles que, de uma forma ou outra, possam contribuir com sua parcela nessa luta incansável e desigual em prol de quem não tem voz a fauna. 


\section{Conclusões}

A partir da edição e vigência da Diretriz Técnica FEPAM no 06/2018 é que as fases de licenciamentos de rodovias no Estado do Rio Grande do Sul passaram a receber um olhar mais técnico e científico, o que se estende para a mortandade da fauna atropelada. A preocupação com a salubridade ambiental traduzida nos regramentos da norma matriz, ao ser transportada para as condicionantes ambientais dos licenciamentos rodoviários, por serem diretrizes gerais, prescindem de uma melhor clareza e especificidade, vez que direcionadas em diferentes amplitudes entre as três rodovias amostrais estudadas.

A efetiva participação das partes envolvidas no processo técnico de licenciamento ambiental de rodovias contribui positivamente para a celeridade processual e evita judicialização. As licenças ambientais devem trazer orientações técnicas claras, precisas e pontuais acerca das condicionantes a serem observadas e respeitadas, o que traz suporte técnico, político e legal ao gestor do procedimento de licenciamento. A clareza nos regramentos a serem cumpridos, tanto pelo licenciador como pelo licenciado, além de ser mais benéfica a ambos, contempla a segurança jurídica e salvaguarda a transparência nos procedimentos fiscalizatórios e renovadores dos licenciamentos. Neste cenário, o chamamento dos licenciados ao processo de licenciamento de rodovias para participação ativa na construção de alternativas viáveis e benéficas a ambas as partes, agrega valores econômicos, reduz a morosidade e evita imbróglios jurídicos, onde todos ganham, em especial o ambiente e a fauna.

\section{Agradecimentos}

Agrademos ao analista ambiental Estevão Barbieri Vicente , na etapa de coleta das informações junto à Fundação Estadual de Proteção Ambiental Henrique Luiz Roessler (FEPAM). Agradecemos também ao Prof. Andreas Kindel (UFRGS) pela contribuição com valorosas informações e questionamentos durante a etapa discussão dos resultados. 0 presente trabalho foi realizado com apoio da Coordenação de Aperfeiçoamento de Pessoal de Nível Superior - Brasil (CAPES) - Código de Financiamento 001.

\section{Conflito de interesses}

Os autores declaram não haver conflito de interesses.

\section{Referências}

Acselrad, H.; Herculano, S.; Pádua, J. A. (Org.). Justiça ambiental e cidadania. Rio de Janeiro: Relume Dumará, 2004.

Ahern, J. L.; Jennings, B.; Fenstermacher, P.; Warren, N.; Charney, S.; Jackson, J.; Mullin, Z.; Kotval, S.; Brena, S.; Civjan, S. A.; Carr. E. Issues and methods for transdisciplinary planning of combined wildlife and pedestrian highway crossings. Transportation Research Record Journal of the Transportation Research Board, v. 2123, n. 1, p. 129-136, 2009. https://doi.org/10.3141/2123-14

Almeida, M. C.; Azeda, N. G.; Pinto-Correia, T. The effects of grazing management in montado fragmentation and heterogeneity. Agroforestry Systems, v. 90, p. 69-85, 2016. https://doi.org/10.1007/s10457-014-9778-2

Bager, A.; Lucas, P. S.; Bourscheit, A.; Kuczach, A.; Maia, B. Os caminhos da conservação da biodiversidade brasileira frente aos impactos da infraestrutura. Biodiversidade Brasileira, v. 6, n, 1, p. 75-86, 2016. 
Bager, A.; Piedras, S. R. N.; Pereira, T. S. M.; Hobus, Q. Fauna selvagem e atropelamento: diagnóstico do conhecimento científico brasileiro. In: Bager A. (Ed.). Áreas protegidas: repensando as escalas de atuação. Porto Alegre: Armazém Digital, 2007.

Bager, A.; Rosa, C. A. Influence of sampling effort on the estimated richness of road-killed vertebrate wildlife. Environmental Management, v. 47, n. 5, p.851-858, 2011. https://doi.org/10.1007/s00267-011-9656-x

Bergallo, H. G.; Vera y Conde, C. F. O Parque Nacional do Iguaçu e a estrada do Colono. Ciência Hoje, v. 29, p. 37-39, 2001.

Brasil. Constituição da República Federativa do Brasil de 1988. Disponível em: <http://www.planalto.gov.br/ccivil_03/constituicao/constituicao.htm>. Acesso em: 03 mar. 2021.

Brasil. Instrução Normativa IBAMA no 13, de 19 de julho de 2013. Estabelece os procedimentos para padronização metodológica dos planos de amostragem de fauna exigidos nos estudos ambientais necessários para o licenciamento ambiental de rodovias e ferrovias. Disponível em: <http://www.ibama.gov.br/component/legislacao/?view= legislacao\&legislacao=130350>. Acesso em: 10. mar. 2021.

Brasil. Lei no 6.938, de 31 de agosto de 1981. Dispõe sobre a Política Nacional do Meio Ambiente, seus fins e mecanismos de formulação e aplicação, e dá outras providências. Disponível em: <http://www.planalto.gov.br/ccivil_03/leis/16938.htm>. Acesso em: 03 mar. 2021.

Brasil. Lei no 9.605, de 12 de fevereiro de 1998. Dispõe sobre as sanções penais e administrativas derivadas de condutas e atividades lesivas ao meio ambiente, e dá outras providências. Disponível em: <http://www.planalto.gov.br/ccivil_03/leis/19605.htm>. Acesso em: 03 mar. 2021.

Brasil. Lei no 9.985, de 18 de julho de 2000. Regulamenta o art. 225, § 1ํㅡ, incisos I, II, III e VII da Constituição Federal, institui o Sistema Nacional de Unidades de Conservação da Natureza e dá outras providências. Disponível em: <http://www.planalto.gov.br/ ccivil_03/leis/19985.htm>. Acesso em: 03 mar. 2021.

Brasil. Lei no 12.651, de 25 de maio de 2012. Dispõe sobre a proteção da vegetação nativa; altera as Leis $\mathrm{n}^{\text {os }}$ 6.938, de 31 de agosto de 1981, 9.393, de 19 de dezembro de 1996, e 11.428, de 22 de dezembro de 2006; revoga as Leis $\mathrm{n}^{\text {os }} 4.771$, de 15 de setembro de 1965, e 7.754, de 14 de abril de 1989, e a Medida Provisória no 2.166-67, de 24 de agosto de 2001; e dá outras providências. Disponível em: <http://www.planalto.gov.br/ccivil_03/_ato2011-2014/2012/lei/l12651.htm>. Acesso em: 06 mar. 2021.

Brasil. Resolução CONAMA no 1, de 23 de janeiro de 1986. Dispõe sobre critérios básicos e diretrizes gerais para a avaliação de impacto ambiental. Disponível em: <http://conama.mma.gov.br/?option=com_sisconama\&task=arquivo.download\&id=745>. Acesso em: 06 mar. 2021.

Brasil. Resolução CONAMA no 237, de 19 de dezembro de 1997. Dispõe sobre a revisão e complementação dos procedimentos e critérios utilizados para o licenciamento ambiental. Disponível em: <http://conama.mma.gov.br/?option=com sisconama\& task=arquivo.download\&id=237>. Acesso em: 06 mar. 2021.

Câmara, J. B. D. Governança ambiental no Brasil: ecos do passado. Revista de Sociologia e

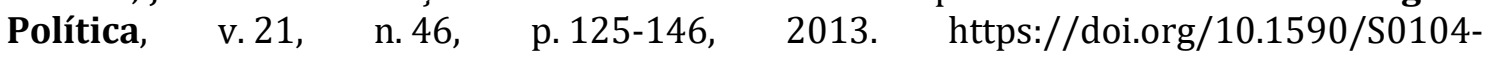
44782013000200008 
CNT - Confederação Nacional do Transporte. Anuário. 2020. Disponível em: <http://anuariodotransporte.cnt.org.br/2017/>. Acesso em: 06 mar. 2021.

Coffin, A. W. From roadkill to road ecology: A review of the ecological effects of roads. $\begin{array}{llllll}\text { Journal of Transport Geography, } & \text { v. 15, } & \text { n. 5, } & \text { p. 396-406, }\end{array}$ https://doi.org/10.1016/j.jtrangeo.2006.11.006

DNIT - Departamento nacional de infraestrutura de transportes. Infraestrutura. 2015. Disponível em: <http://www.gov.br/infraestrutura/pt-br/assuntos/noticias/ultimasnoticias/dnit-regulariza-ambientalmente-51-074-km-de-rodovias.htm>. Acesso em: 23 abr. 2021.

EGR - Empresa Gaúcha de Rodovias. Rodovias: ERS-135. 2021. Disponível em: <http://www.egr.rs.gov.br/conteudo/838/ers-135.htm>. Acesso em: 06 mar. 2021.

Fensterseifer, T. Direitos fundamentais e proteção do ambiente. Porto Alegre: Livraria do Advogado, 2008.

Forman, R. T.; Alexander, L. E. Roads and their major ecological effects. Annual Review of Ecology and Systematics, v. 29, p. 207-231, 1998.

Garcia, M. G. F. P. D. 0 lugar do direito na proteção do ambiente. Coimbra: Almedina, 2007.

Hartmann, P. A.; Hartmann, M. T.; Martins, M. Snake road mortality in a protected area in the Atlantic Forest of Southeastern Brazil. South American Journal of Herpetology, v. 6, p. 35-42, 2011. https://doi.org/10.2994/057.006.0105

Jaeger, J. A. G. Improving environmental impact assessment and road planning at the landscape scale. In: Van Der Ree, R.; Smith, D. J.; Grillo, C. (Eds.). Handbook of Road Ecology. West Sussex: John Wiley \& Sons, 2015.

Jaeger, J. A. G.; Bowman, J.; Brennan, J.; Fahrig, L.; Bert, D.; Bouchard, J. Predicting when animal populations are at risk from roads: An interactive model of road avoidance behavior. Ecological Modelling, v. 185, n. 2/4, p.329-348, 2005. https://doi.org/10.1016/j.ecolmodel.2004.12.015

Karlson, M.; Mörtberg, U.; Balfors, B. Road ecology in environmental impact assessment. Environmental Impact Assessment Review, v. 48, p.10-19, 2014. https://doi.org/10.1016/j.eiar.2014.04.002

Kindel, A.; Teixeira, F. Z.; Goncalves, L. O.; Coelho, I. P.; Beduschi, J.; Schuck, G.; Lemos, C.; Herkenhoff, C.; Leite, L. C. L.; Silveira, L. F.; Silva, S. A.; Sana, D. A. Following the 'why? what? and how?' Schema to improve road-kill evaluation in environmental impact assessments of Southern Brazil. Oecologia Australis, v.21, p. 256-267, 2017. https://doi.org/10.4257/oeco.2017.2103.03

Lauxen, M. S. A mitigação dos impactos de rodovias sobre a fauna. Brasília: IBAMA, 2012.

Martinazzo, L. N. História ambiental do Alto Uruguai: colonização, desenvolvimento e transformações na paisagem. Lajeado: Centro Universitário UNIVATES, 2011. (Dissertação de mestrado).

Mendes, G. F. Direitos fundamentais e controle de constitucionalidade. São Paulo: Saraiva, 2004.

Metzger, J. P. Conservation issues in the Brazilian Atlantic Forest. Biological Conservation, v. 142, p. 1138-1140, 2009. https://doi.org/10.1016/j.biocon.2008.10.012 
Perz, S. G.; Warren, J. W.; David P.; Kennedy, D. P. Contributions of racial-ethnic reclassification and demographic processes to indigenous population resurgence: The case of Brazil. Latin American Research Review, v. 42, n. 3, p. 7-33, 2008. https://doi.org/10.1353/lar.0.0019

Piran, N. Contribuição à caracterização do Alto Uruguai (RS): breve releitura e novos desafios. Perspectiva: Erechim, v. 39, n 53-64, 2015.

Rio Grande do Sul. Diretriz Técnica FEPAM no 06, de 20 de dezembro de 2018. Diretriz técnica referente ao termo de referência para o monitoramento de fauna em rodovias. Disponível em: <http://www.fepam.rs.gov.br/licenciamento/area4/17.asp>. Acesso em: 10 mar. 2021.

Rio Grande do Sul. Zoneamento ambiental da silvicultura: diretrizes da silvicultura por unidade de paisagem e bacia hidrográfica. Porto Alegre: Secretaria Estadual do Meio Ambiente, 2010.

Santana, G. S. Fatores influentes sobre atropelamentos de vertebrados na região central do Rio Grande do Sul, Brasil. Revista Neotropical Biology and Conservation, v. 7, n. 1, p. 26-40, 2012. https://doi.org/10.4013/nbc.2012.71.05

Sarlet, I. W. Dignidade da pessoa humana e direitos fundamentais na Constituição Federal de 1988. Porto Alegre: Livraria do Advogado, 2010.

Silva, J. C. L. Direito Ambiental Constitucional. São Paulo: Saraiva, 2013.

Silva, L.C.P. B. A geração de impacto ambiental das obras de engenharia. Revista Biodiversidade, v. 16, n. 1, p. 179-188, 2017.

Silva-Sánchez, S. S. Cidadania ambiental: novos direitos no Brasil. São Paulo: Humanitas, FFLCH, USP, 2000.

Steinmetz, W. A vinculação dos particulares a direitos fundamentais. São Paulo: Malheiros, 2004.

Trombulak, S. C.; Frissell, C. A. Review of ecological effects of roads on terrestrial and aquatic communities. Conservation Biology, v. 14, n. 1, p.18-30, 2000. https://doi.org/10.1046/j.1523-1739.2000.99084.x

Van Der Ree, R.; Smith, D. J.; Grilo, C. The ecological effects of linear infrastructure and traffic: Challenges and opportunities of rapid global growth. In: Van Der Ree, R., Smith, D.; Grilo, C. (Eds.). Handbook of Road Ecology. West Sussex: John Wiley \& Sons, 2015.

Informação da Licença: Este é um artigo Open Access distribuído sob os termos da Licença Creative Commons Attribution, que permite uso irrestrito, distribuição e reprodução em qualquer meio, desde que a obra original seja devidamente citada. 